\title{
Successful Treatment of Unknown Drug-Induced Catatonia with Intravenous Midazolam in a Nine-Year-Old Girl
}

Sinan OĞUZi id , Nilden TUYGUN ${ }^{1}$ id , Selman KESICi ${ }^{2}$ id , Can Demir KARACAN ${ }^{1}$ id

${ }^{1}$ Clinic of Pediatric Emergency, Ankara Dr. Sami Ulus Gynaecology, Children's Health and Diseases Training and Research Hospital, Ankara, Turkey ${ }^{2}$ Clinic of Pediatric Intensive Care, Ankara Dr. Sami Ulus Gynaecology, Children's Health and Diseases Training and Research Hospital, Ankara, Turkey

\section{ABSTRACT}

Catatonia is a syndrome characterized by symptoms such as perseveration, passive obedience, mutism, immobility, negativism, stereotypes, mannerisms, and echo phenomenon. It is usually seen with psychiatric disorders. A nine-year-old girl was admitted to the emergency unit with symptoms of unresponsiveness and tonic contractions after using an unknown drug. Mutism and rigidity were detected in the conscious state with waxy flexibility. Catatonia symptoms resolved after intravenous midazolam treatment. In this paper, we aimed to discuss catatonia, which is rarely observed in pediatric practice.

Keywords: Catatonia, childhood, benzodiazepines

\section{Introduction}

Catatonia, which is generally seen in severe psychiatric diseases, is a syndrome characterized by mutism, immobility, negativism, stereotype, mannerism, echo phenomena, perseveration, and passive obedience $(1,2)$. Although it was previously considered to occur only in patients with schizophrenia, it has been recently seen in patients with psychiatric diseases, such as bipolar disorder and major depression, medical and neurological diseases, metabolic disorders, and after the intake of an antipsychotic drug (3). It is important to perform the differential diagnosis of catatonia and to establish its diagnosis for an appropriate treatment. First, some life-threatening conditions, such as neuroleptic malignant syndrome, encephalitis, nonconvulsive status epilepticus, and intoxication, should be investigated. Although the pathophysiology of catatonia is not exactly known, it is thought to develop due to neurotransmitter dysfunction. Positive outcomes obtained with the use of benzodiazepines in the treatment support this hypothesis $(3,4)$.

In this study, a 9-year-old girl with catatonia who was successfully treated with intravenous midazolam and her differential diagnosis were presented with contemporary literature. We aimed to emphasize that catatonia could be seen even in childhood.

\section{Case presentation}

A 9-year-old girl who was previously healthy was admitted to the emergency department due to the sudden incidence of throwing her head to the left and back and tonic contraction in the whole body. She was conscious, and her vital signs were normal. She partially obeyed instructions. No abnormality was found in her own and family histories. She also had no history of any medication or trauma. Physical examination revealed waxy flexibility, mutism, and rigidity in the entire body. She was considered to have catatonia according to these findings and was administered $0.1 \mathrm{mg} / \mathrm{kg}$ intravenous midazolam; her complaints decreased in the next $15 \mathrm{~min}$. The results of complete blood count, biochemistry, blood gas, thyroid function, and electrocardiogram were normal. No pathological finding was detected on computed

Cite this article as: Oğuz S, Tuygun N, Kesici S, Karacan CD. Successful Treatment of Unknown Drug-Induced Catatonia with Intravenous Midazolam in a NineYear-Old Girl. Bezmialem Science 2018; 6: 70-2.

This study was presented at the "5. Academy of Pediatrics Specialist Academy (PUADER) Congress ", "10-14 April 2016", "izmir, Turkey". 
Table 1. There should be 3 or more of the following 12 findings for the diagnosis of catatonia (4)

Stupor (no psychomotor activity, not actively relating to the environment)

Catalepsy (passive induction of a posture held against gravity)

Waxy flexibility (resistance to positioning by the examiner)

Mutism (no or very little verbal response)

Negativism (no response to external stimuli)

Posturing (maintenance of a posture against gravity)

Mannerism (caricature of normal actions)

Stereotype (abnormally frequent and repetitive, non-goal-directed movements)

Agitation

Grimacing

Echolalia (mimicking other's speech)

Echopraxia (mimicking other's movements)

tomography of the brain. The patient, whose complaints were relieved, stated that she had taken a pink-colored unknown drug that she obtained on the way to school. It was learned that sleepiness had begun after $4 \mathrm{~h}$ of ingesting the drug, and contractions had begun approximately after $24 \mathrm{~h}$. Because her complaints recurred during follow-up, she was administered intravenous midazolam $(0.1 \mathrm{mg} / \mathrm{kg} / \mathrm{h})$, and her complaints rapidly regressed. After 12-h infusion, midazolam administration was stopped. Because she had no complaints anymore and the results of physical examination were normal, she was discharged. The patient showed no problem in the control examination performed after 3 days and was followed up. In the control examination after 1 month, magnetic resonance imaging of the brain was normal, and no additional complaint or finding was observed. Therefore, her follow-up was ended. Written informed consent for the study was received from the family of the patient.

\section{Discussion}

Mutism, negativism, echolalia, echopraxia, and waxy flexibility are the most important clinical findings in catatonia. This condition can be divided into three groups (catatonia associated with 1) psychiatric diseases, 2) medical diseases, and 3) unknown origin), depending on the underlying cause. Diagnostic criteria are shown in Table 1.

The most important factor causing catatonia is psychiatric disease, particularly schizophrenia (5). Moreover, other psychiatric disorders, such as bipolar disorder, major depression, autism spectrum disorder, and delirium, can also accompany catatonia (6). In our case, psychiatric disorders were initially eliminated because our patient's findings were acute; she had no history of any psychiatric disease, and her complaints developed after the intake of a drug.
Healthcare staff in the emergency unit should be alert about life-threatening conditions, such as neuroleptic malignant syndrome, encephalitis, nonconvulsive status epilepticus, and acute psychosis, which can lead to catatonia. Neuroleptic malignant syndrome is a serious condition that is potentially life-threatening and is characterized by high fever, muscle rigidity, autonomic dysfunction, and changes in consciousness. It is often associated with antipsychotic medications (7). Because our patient was conscious and had no accompanying abnormalities in her vital signs, this condition was ruled out.

Complete blood count, liver and kidney function tests, serum creatine kinase and ceruloplasmin levels, and toxicological tests can be required for patients with catatonia. In our case, any abnormal pathological finding was not detected in laboratory analyses and toxicology tests of the patient. In the literature, an association between subclinical hypothyroidism and catatonia has been reported. However, the results of thyroid function tests were normal in our patient.

Catatonia cases associated with arachnoid cyst and hydrocephaly have also been reported. The evaluation of the brain through computed tomography and/or magnetic resonance imaging may be required with regard to intracranial pathologies (2). In our case, the results of imaging techniques performed in the early period and in the control examinations were normal.

Patients presenting with acute psychosis or catatonia should be evaluated in terms of encephalitis. Acute psychiatric disorders and seizure are remarkable in such patients. Electroencephalography can be used for the differentiation of seizures (2). In our case, this condition was also eliminated because the patient did not clinically have seizure or changes in her consciousness, had a history of an unknown drug, rapidly responded to benzodiazepine therapy, and showed rapid improvement of symptoms.

Catatonia has been associated with many medications. It can also occur due to the toxic effect of drugs or withdrawal of alcohol, gabapentin, and benzodiazepine-derived drugs (8-10). In our case, the development of sleepiness in $4 \mathrm{~h}$ following the intake of an unknown drug and contractions after approximately $24 \mathrm{~h}$ primarily suggested sedative-hypnotic drug withdrawal.

\section{Conclusion}

Catatonia, which is a rarely encountered clinical condition, can be caused by psychiatric diseases, neurological and metabolic disorders, cerebrovascular diseases, tumors, toxins, or drugs. In catatonia cases, the underlying disorder should be investigated at the beginning and should be treated. While benzodiazepines are mainly used in the treatment, electroconvulsive treatment can be required in cases without any response. 
Informed Consent: Written informed consent was obtained from family of patient.

Peer-review: Externally peer-reviewed.

Author Contributions: Concept - S.O., N.T., S.K., C.D.K.; Design - S.O., N.T., S.K., C.D.K.; Supervision - S.O., N.T., S.K., C.D.K.; Resource - S.O., N.T.; Materials - S.O.; Data Collection and/or Processing - S.O., S.K.; Analysis and/or Interpretation - S.O., N.T.; Literature Search - S.O., S.K.; Writing - S.O.; Critical Reviews - N.T., C.D.K.

Conflict of Interest: No conflict of interest was declared by the authors.

Financial Disclosure: The authors declared that this study has received no financial support.

\section{References}

1. Francis A. Catatonia: diagnosis, classification, and treatment. Current psychiatry reports. 2010; 12: 180-5. [CrossRef]
2. Özkul A, Akyol A, Tamam Y. Malignant Catatonia. Cur Appr Psychiatr 2010; 2: 595-608.

3. Weder ND, Muralee S, Penland H, Tampi RR. Catatonia: a review. Ann Clin Psychiatr 2008; 20: 97-107. [CrossRef]

4. American Psychiatric Association. Diagnostic and Statistical Manual of Mental Disorders, Fifth Edition (DSM-5). Arlington 2013.

5. Fink M, Taylor MA. The many varieties of catatonia. Eur Arch Psychiatr Clin Neuroscien 2001; 251(Suppl 1): I8-13. [CrossRef]

6. Lin CC, Hung YY, Tsai MC, Huang TL. Relapses and recurrences of catatonia: 30-case analysis and literature review. Comprehensive Psychiatr 2016; 66: 157-65. [CrossRef]

7. Tse L, Barr AM, Scarapicchia V, Vila-Rodriguez F. Neuroleptic Malignant Syndrome: A Review from a Clinically Oriented Perspective. Current Neuropharmacol 2015; 13: 395-406. [CrossRef]

8. Sivakumar T, Yadav A, Sood M, Khandelwal SK. Lorazepam withdrawal catatonia: a case report. Asian J Psychiatr 2013; 6: 620-1. [CrossRef]

9. Geoffroy PA, Rolland B, Cottencin O. Catatonia and alcohol withdrawal: a complex and underestimated syndrome. Alcohol Alcohol 2012; 47: 288-90. [CrossRef]

10. Rosebush PI, MacQueen GM, Mazurek MF. Catatonia following gabapentin withdrawal. J Clin Psychopharmacol 1999; 19: 188-9. [CrossRef] 